\title{
Medicinal Plants used by Koch Rajbangshi of North Salmara Subdivision, Bongaigaon, Assam, India
}

\author{
Ashoke Kumar Das ${ }^{1 *}$, Manabendra Ray Choudhury ${ }^{2}$ and Gajen Chandra Sharma ${ }^{3}$ \\ ${ }^{1}$ Department of Botany, Abhayapuri College, Abhayapuri, Assam - 783384, India \\ ${ }^{2}$ Department of Ecology and Environmental Science, Assam University, Assam - 788001, India \\ ${ }^{3}$ Department of Botany, Gauhati University, Assam - 781014, India \\ *E-mail: das.ashoke09@yahoo.co.in
}

Received: 15.04.2013, Accepted: 17.06.2013

\begin{abstract}
A total of 73 medicinal plants belonging to 44 families of angiosperms were found to be used in the healing practice of 36 types of diseases including diabetics, heart problem, and neurological disorders by Koch Rajbangshi people of North Salmara subdivision of Bongaigaon district, Assam. More use of leaf was found in disease treatment than other parts of plant. Among the plants species 49 were common in occurrence, 19 species less common and 5 species viz., Aristolochia indica L., Asparagus recemosus Willd., Cissus quadrangularis L., Garcinia morella (Gaertn.) Desv and Rauvolfia serpentina Benth. were in rare category in the study area.
\end{abstract}

Key words: Koch Rajbangshi, Medicinal plant, Ethnomedicine, Ancient tribe, Assam

\section{Introduction}

In recent years, study of ethnobotany has been given much attention due to its wide application in community health care. In India and other parts of Asia many works have been done aimed at documenting knowledge of traditional medicinal plants. Indian medical heritage is perhaps the longest unbroken one in human civilization. The record of medicinal use of plants are found in various repositories like Rigveda, Atharvaveda, Ayurveda, Charaka Samhita and Susruta Samhita etc., besides Unani and Siddha.

North East India inhabiting more than 150 tribes speaking as many languages is a region of melting pot of variegated cultural mosaic of people and races, and ethnic tapestry of many hues and shades (Dutta and Dutta, 2005).

Koch Rajbangshi or Rajbangshi is one of the most ancient tribe of Assam. They belong to the Mongoloid race and are very closely allied to Kacharies and Garos (Gait, 1906; Barua et al., 1999). Koches group of people belong to Kachari and other tribes which converted themselves to Hinduism; while Rajbangshi literally means the 'Royal community'. The term Koch and Rajbangshi are both synonymous and indicate the tribe which once dominated North Bengal, Goalpara and North side of Brahmaputra River (Gait, 1906). They use to speak their own dialect (Barua et al., 1999) called Rajbangshi language; it is a mixture of 
Ashoke Kumar Das, Manabendra Ray Choudhury and Gajen Chandra Sharma

/ Our Nature (2013) 11(1): 45-53

Assamese, Bangla and Hindi. In Rajbangshi language, the use of Sanskrit is highest with a mixture of Urdu, Hindi, Prakit and Pali (Choudhury, 1969). The original Koch Rajbangshi language is now practically extinct, but the trace of it is found in the present form of language (Gait, 1906). They have their rich cultural heritage. They exhibit their culture by observing Bisuwa during month of April. They perform ritual believes like 'Bansh Puja' which means the worship of bamboo; Garja puja, worship of village deity; Maroi Puja which means worship of Maa Manasha (Goddess of Snake). They are distributed all over Assam and North Bengal, eastern part of Bihar, Meghalaya, Eastern Nepal and in some parts of Bangladesh. They are the most dominant tribe in Bongaigaon District of Assam which is the part of old Bijni Raj Estate (Choudhury, 1969).

The Koch Rajbangshi people use various wild and cultivated plants as medicine for curing different diseases. They completely or partially depend upon these plants for curing various diseases. The plants are mostly used as first aid treatment in most of the diseases. In almost every village there is a medical man who generally knows the traditional uses of the plants. There are some ritual believes also associated with these medicinal plants. A good number of these plants are also included in their daily diet. Above all, the plants have also some market value, thus playing an important socio-economic role among the people of the tribe. With the use of modern health care system, the traditional health care system is now at a verge of extinction. Previously,
Barua et al. (1999) worked on the ethnobotany of Rajbanshis of Assam and recorded the use of 58 plant species belonging to 37 families; they found most of the plants used as antidote, bodyache, diarrhoea and sexual ailment of human (Barua et al. 1999). In the present work, we tried to document the plants used for the medicinal purposes in the North Salmara region. We document all the plants along with its uses with an aim to create a database of traditional knowledge and use pattern of plants by Koch Rajbangshi people in the region.

\section{Study Area}

The study was conducted during 2009 to 2010 in Choutaki, Deohati and Kakoijana villages of North-Salmara subdivision of Bongaigaon district (Fig. 1). The villages are dominated by Koch Rajbangshi people. The district is located in the western part of Assam $\quad\left(26^{\circ} 15^{\prime}-26^{\circ} 30^{\prime} \mathrm{N}\right.$ and $90^{\circ} 28^{\prime}-$ $\left.90^{\circ} 50^{\prime} \mathrm{E}\right)$, India. The soils of the study area are light gray to light brown in colour and are less compact type consisting of ground sand, silts and clays. The soil of the District is generally acidic (www.bongaigaon.nic.in) The study area falls in subtropical climate zone. Humid summer with heavy rain fall in the monsoon and moderately cold winter are the characteristics of the area. The maximum mean temperature is 30 to $32^{\circ} \mathrm{C}$ in the month of July while the minimum is recorded in the month of January $\left(12^{\circ} \mathrm{C}\right)$. The average rainfall in monsoon range between 900 to $1100 \mathrm{~mm}$ and in winter it is 0 to $20 \mathrm{~mm}$ (Regional Meteorological Centre, Guwahati). 


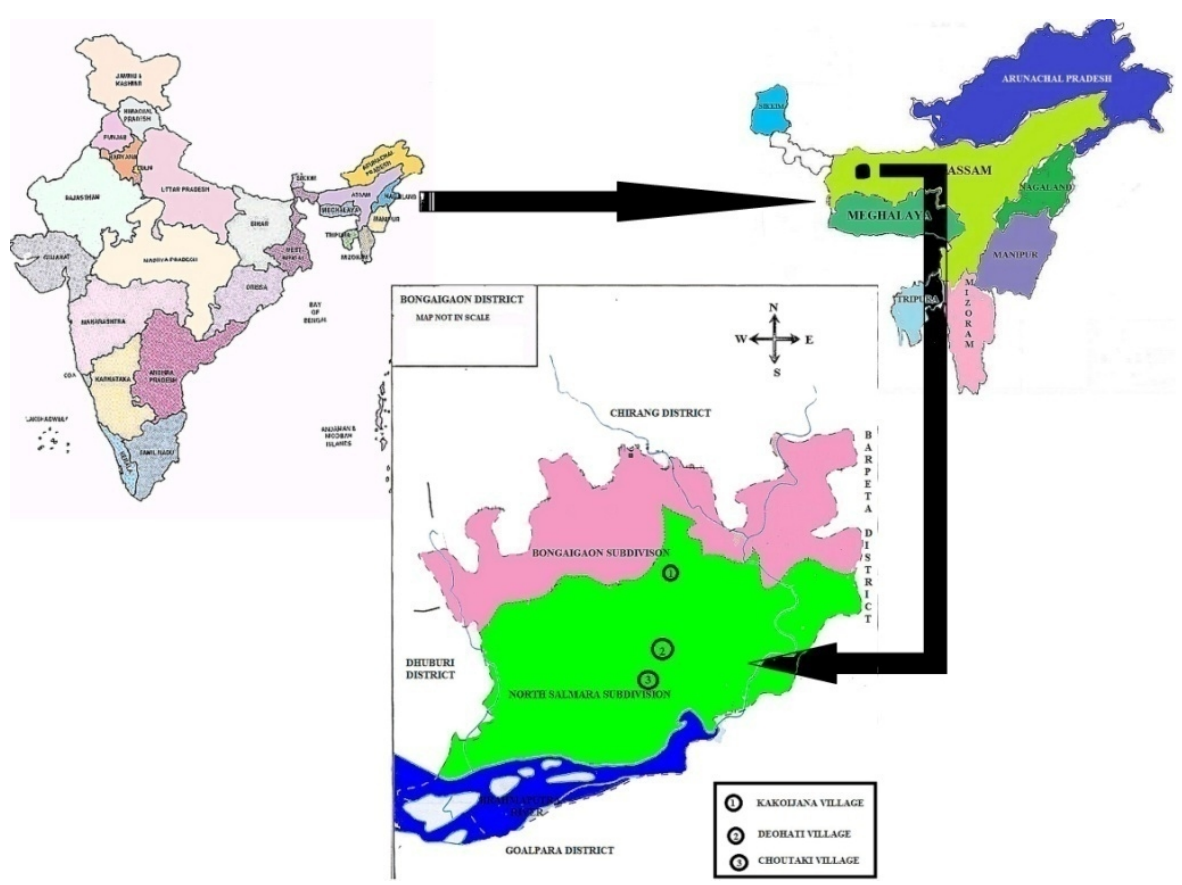

Figure 1. Map of the North Salmara sub-division of Bongaigaon District, Assam.

\section{Materials and methods}

In our study, snowball sampling procedure was adopted to squeeze out the knowledge in a short time. Snowball sampling begins with the few respondents who are known and available in the study area. Subsequently, these respondents give other names who meet the criteria of research, who in turn give more new names (Ahuja, 2011). Open ended interview method was followed and semi structured questionnaires were used to collect the data. Open ended interviews are essentially casual conversations which can reveal detailed life histories (Cotton, 1996).

Traditional medicinal practitioners were mainly enquired and information was collected regarding the habitat, type, parts used of the plant. Data on each plant had been recorded with their family, vernacular name, occurrence and process of utilization. The availability of the plant species were also recorded as common, less common and rare.

For making herbarium, specimens were pressed by spraying 10\% formaldehyde. Succulent, bulbous and rhizomatous plants were boiled till the plant turned yellow and pressed properly. Dried specimens were poisoned properly with a saturated solution of $\mathrm{HgCl}_{2}$ dissolved in absolute alcohol and mounted with good quality glue on standard herbarium sheet $\left(42 \times 28 \mathrm{~cm}^{2}\right)$. Field data with collection number, locality, short description, vernacular name, collector's name were transferred from the field notebook to printed label on the right hand corner of the herbarium sheet for ready identification (Jain and Rao, 1977). The collected plants were identified by 
Ashoke Kumar Das, Manabendra Ray Choudhury and Gajen Chandra Sharma

/ Our Nature (2013) 11(1): 45-53

consulting a number of books on the floras of the region especially Flora of British India (Hooker, 1872-1897), Flora of Assam (Kanjilal et al., 1934-1940), and A Hand Book of Scientific Names and Assamese Names of Plants (Bora, 2004). The Herbarium of Botanical Survey of India, Shillong and Herbarium of Gauhati University were also used for identification of plant species. All the herbarium specimens are deposited in the herbaria of Abhayapuri College, Abhayapuri.

\section{Results and discussion}

In our present work, a total of 73 plant species belonging to 44 families (Tab. 1) which are used by the Koch Rajbangshi people in various diseases in their day to day life were recorded. Among them 46 plants are wild and 25 are cultivated, while 3 plant species occur both in natural and cultivated condition. However, there is a significant difference in the use of medicinal plants occurring in nature $(\chi 2=$ 5.8, df $=1, \mathrm{P}<0.05$ ). Among them 65 plants are terrestrial, 5 epiphytic and 3 aquatic. Most of the plants are herbs in habit (Fig. 2). Use of leaf is dominant which is followed by fruit, stem and root and other plant parts (Fig. 3). There is highly significant difference among the use of the plant parts $(\chi 2=104.9, \mathrm{df}=9, \mathrm{P}<0.01)$. Most of the plants are common in occurrence along with five rare plants viz. Aristolochia indica L, Asparagus recemosus Eilld., Cissus quadrangularis L., Rauvolfia serpentina Benth, Garcinia morella (Gaertn.) Desv. These plants are mainly used to cure 36 types of disease (Fig. 4).

The knowledge on wonderful and effective medicines by tribal communities acquired through the experience, are usually passed on by oral traditions as a guarded secret of certain families (Dutta and Dutta, 2005). As the modern civilization has now spread to the most regions of the world, it has made most of the primate societies to break away their cultural and traditional belief and practices. This slow divorcement from culture and tradition has brought about a disintegration of knowledge and practices of plants in their daily life (Das et al., 2008.). The Koch Rajbangshi people are also not separate from the list. A study carried out in Rajasthan shows that $25 \%$ of therapeutic drugs are obtained from plants (Kumar et al., 2003). There are many unknown plants which are still to be studied and observed (Saikia et al., 2010). Hitherto, there is no such record of work done in the Koch Rajbangshi community. Hence, it is important to find out the traditional base of the healthcare system practiced by the Koch Rajbanshi community from the conservation point of view. The tribal people collect some of the important plant species from their surroundings and use according to their own traditional lore (Saikia et al., 2010). Most of the plant species used by local people for medicinal purposes are herbs, which have vast economic importance (Das et al., 2006). In our present work, it is found that the Koch Rajbangshi people use wild plants more than the cultivated ones. They have a similar type of use pattern of herbaceous plants like other records. Koch Rajbanshi people use plant types like tree (15 species) and climber (7 species) for medicinal purpose (Fig. 2).

A study carried out on the ethno medicinal use of wild plants in North Bengal plain found 62 plant species used in 
Ashoke Kumar Das, Manabendra Ray Choudhury and Gajen Chandra Sharma

/ Our Nature (2013) 11(1): 45-53

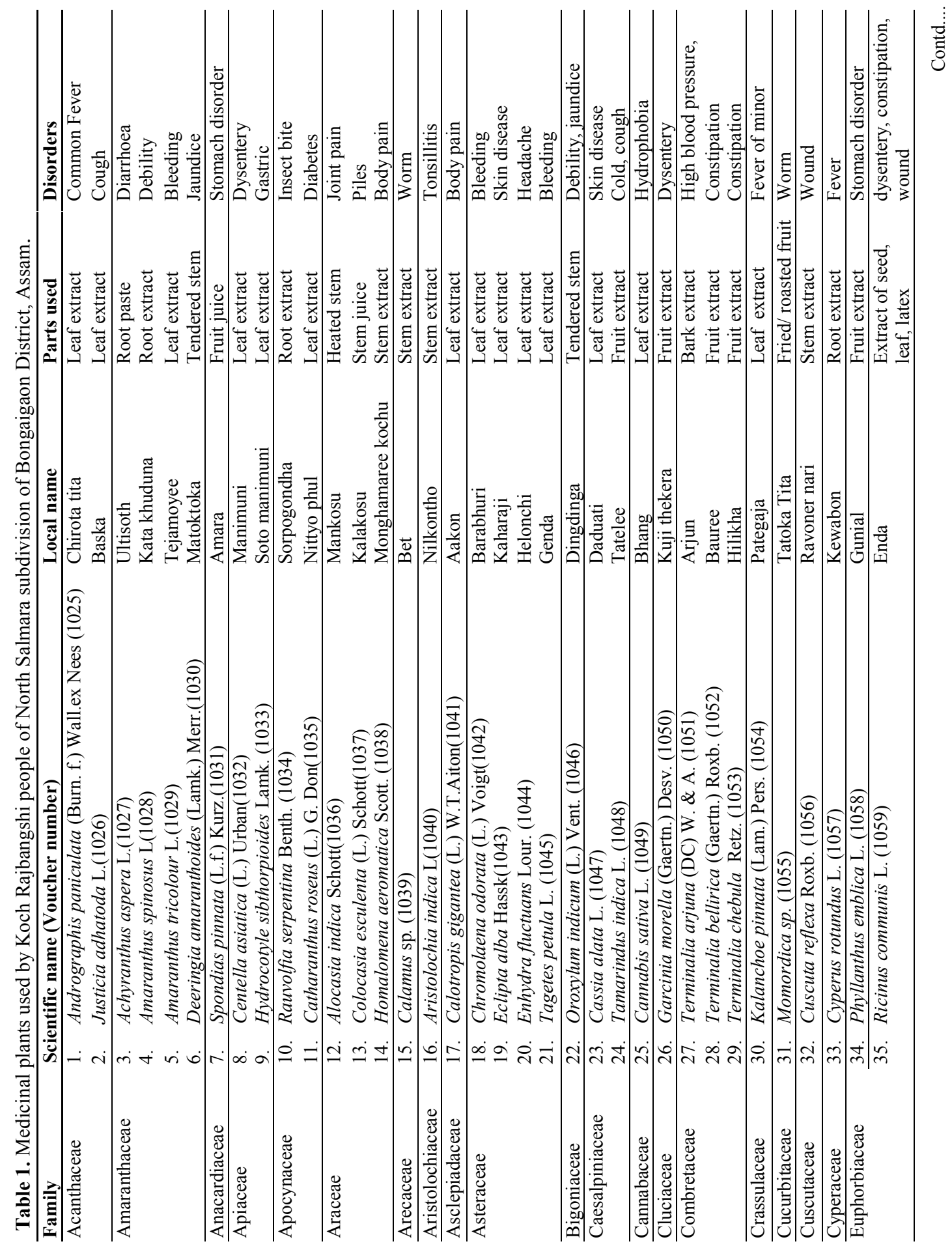




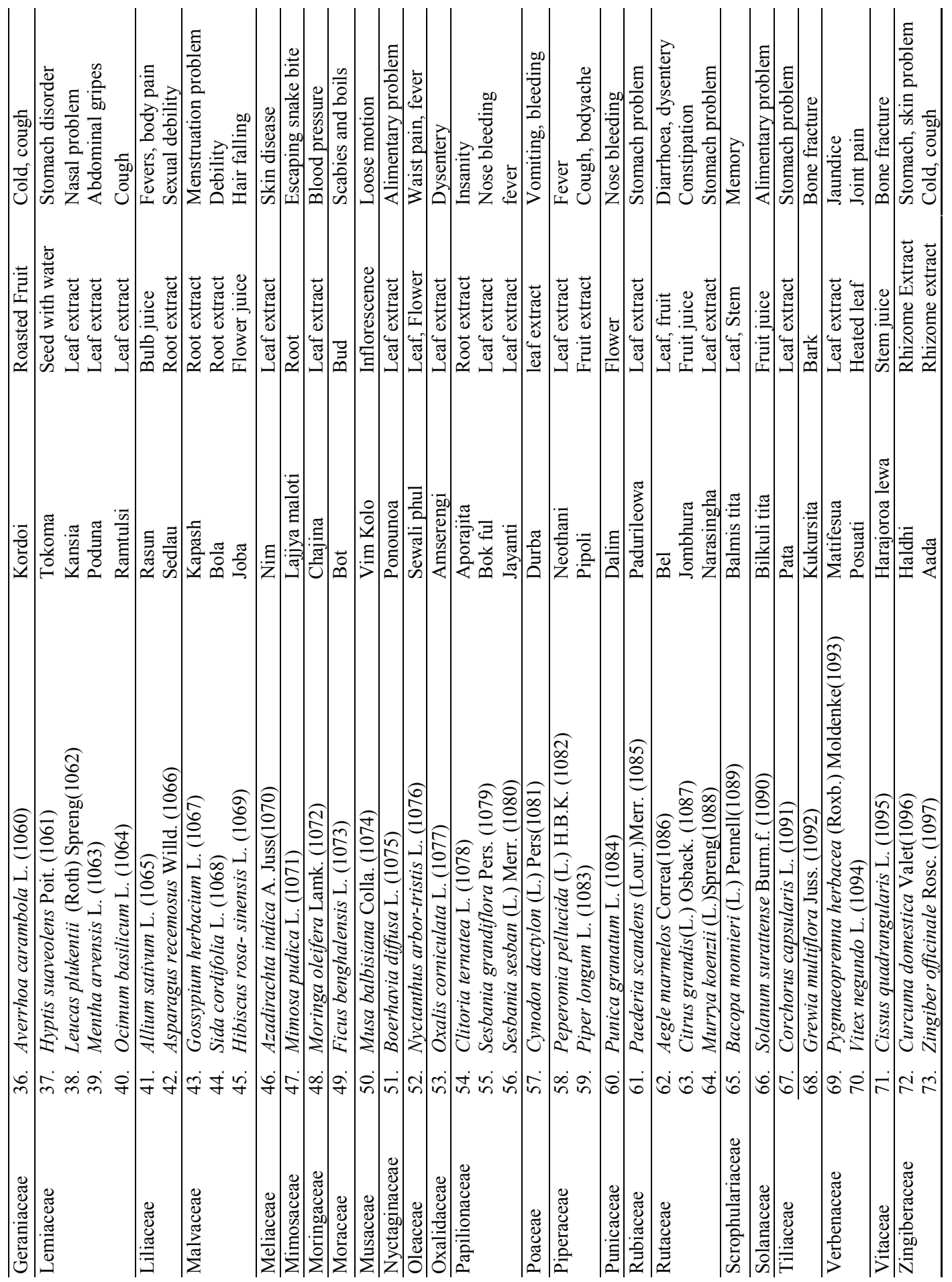


Ashoke Kumar Das, Manabendra Ray Choudhury and Gajen Chandra Sharma

/ Our Nature (2013) 11(1): 45-53

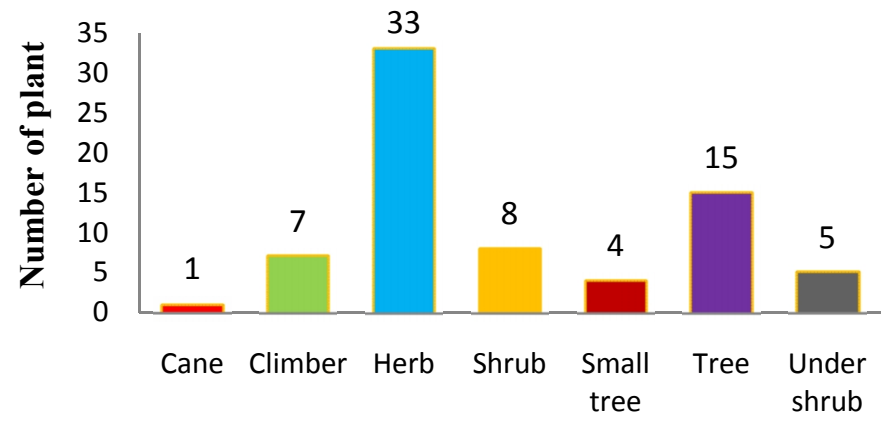

Plant types

Figure 2. Totat number of plant types used as medicine by the Koch Rajbangshis in the North Salmara subdivision of Bongaigaon District, Assam.

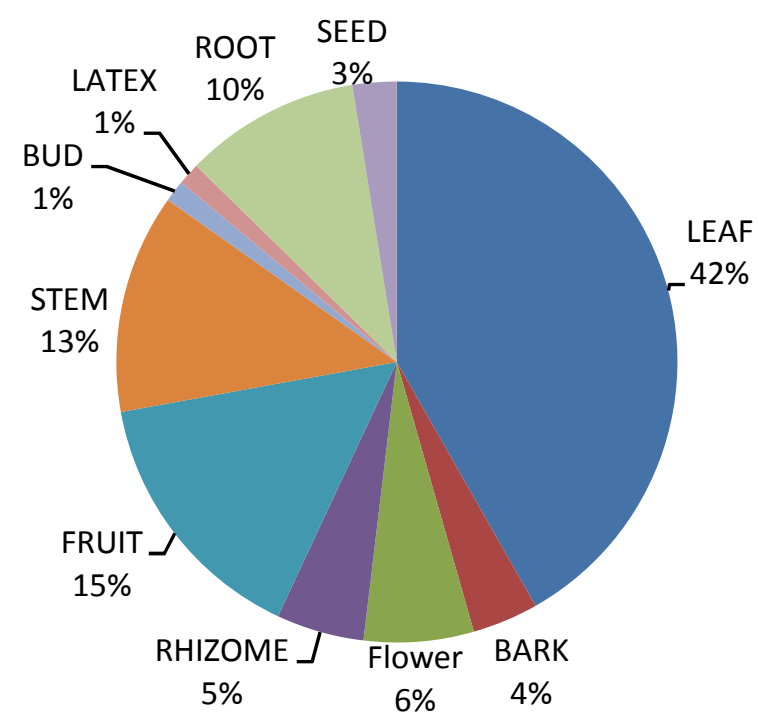

Figure 3. Percentage of the plant parts used for different medicinal purpose by the Koch Rajbangshis of North Salmara subdivision, Bongaigaon, Asssam.

75 different ways of prescriptions of which root and rhizome and root barks are used in 18 cases, stem, stem bark, twigs and petioles in 21 cases, flowers in 1 case, fruits in 6 cases; seeds in 7 cases and the whole plants in 6 cases (Mitra and Mukherjee, 2010). Another study in Jaintia of North
Cachar hills describes that leaf is used in the majority of cases (23 species), followed by fruits (4 species). Different underground plant forms such as root, tuber, rhizome, bulb and pseudo-bulb have also been found to be in use as a source for curing ailments (Sajem and Gosai, 2006). It has been found 
Ashoke Kumar Das, Manabendra Ray Choudhury and Gajen Chandra Sharma

/ Our Nature (2013) 11(1): 45-53

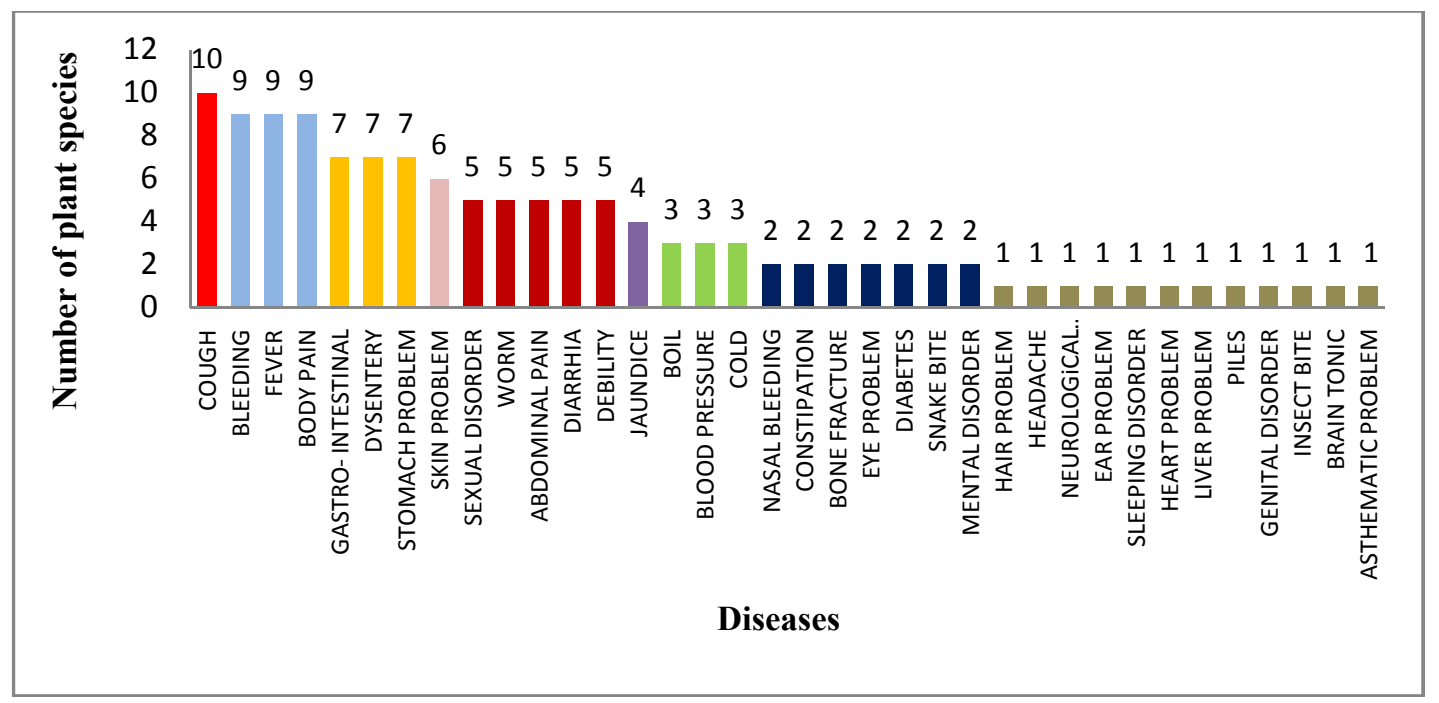

Figure 4. Different diseases cured by traditional healthcare system among the Koch Rajbangshis of North Salmara subdivision, Bongaigaon, Assam.

that the use of aboveground plant parts is higher $(65.38 \%)$ than the underground plant parts (15.38\%) (Dutta Choudhury et al., 2010). Koch Rajbangshi people use leaf part significantly in higher proportion in comparison to other parts including fruit, flower, root, bark, bud, rhizome, latex, and seed. It was found that only 8 types of underground part $(10 \%$ of the total) were used for medicinal purpose (Fig. 3).

In the earlier work, Barua et al. (1999) recorded 58 plant species used by the Rajbanshis of Assam. In the present work, 15 more plant species were recorded than the previous report. The present study shows the Koch Rajbangshi people use 73 plant species to cure 36 types of ailments, mostly in the treatment of cough (10 species), followed by fever (9 species), bleeding (9 species), body pain (9 species), gastrointestinal (7 species), dysentery (7 species), stomach problem (7 species), diabetic (2 species), heart problem (1 species). The use of the plants in curing the ailments differs significantly. Sajem et al. (2006) also found 39 medicinal plant species used in curing about 30 types of ailments in Jayantias of North Cachar hills, of which the highest numbers of plant species (20 species) were used for the treatment of gastrointestinal disorders such as indigestion and constipation. About 8 medicinal plant species were used in curing cough and cold, and 5 medicinal plant species were used for healing cuts and wounds (Sajem and Gosai, 2006). Sajem et al. (2008) found 6 species of plants which are included in the Red Data Book of Indian Plants (Sajem et al., 2008). In our study we have recorded five species of rare plants which are used for medicinal purpose by the Koch Rajbanshi people.

Thus it can be concluded that the Koch Rajbangshi people have deep knowledge on the use of plants (both wild and cultivated) in treatment of various ailments like other 


\section{Ashoke Kumar Das, Manabendra Ray Choudhury and Gajen Chandra Sharma / Our Nature (2013) 11(1): 45-53}

ethnic groups of Assam as well as North East India.

\section{Acknowledgements}

We would like to thank the Head of the Botany Department, Gauhati University and Joint Director of Botanical Survey of India, North Eastern Circle, Shillong for identification of plant species. Thanks are also due to the respondents of the study area who provided us necessary information at the time of our research. The authors also like to thank Jayanta Kr. Ray and Freeman Boro for their kind suggestions.

\section{References}

Ahuja, R. 2011. Research method. Rawat publications. 181p.

Barua, K.N., I.C. Barua and M. Das 1999 Ethnobotany of Rajbanshis of Assam. Journal of Economic and Taxonomic Botany 23(2): 609-614.

Bora, A. 2004. A hand book of scientific names and Assamese names of plants. Aaranyak. Guwahati.

Choudhury, A.C. 1969. Koch Rajbonshi jono gosthir itihas aru sanskriti. Unic printers.

Cotton, C.M. 1996. Ethnobotany principles and applications. John willey and sons Ltd.

Das, A.K., B.K. Dutta and G.D. Sharma 2008 Medicinal plants used by different tribes of Cachar district, Assam. Indian Journal of Traditional Knowledge 7(3): 446-454.

Das, N.J., S.P. Saikia and K. Devi 2006. Medicinal plants of North Kamrup district of Assam used in primary healthcare system. Indian Journal of Traditional Knowledge 5(4): 489-493.
Dutta Choudhury, M., M. Bawari and L.S. Singha 2010. Some antipyretic ethno-medicinal plants of Manipuri community of Barak valley, Assam, India. Ethnobotanical Leaflets 14: 21-28.

Dutta, B.K. and P.K. Dutta 2005. Potential of ethnobotanical studies in North East India: An overview. Indian Journal of Traditional Knowledge 4(1): 7-14.

Gait, E.A. 1906. A history of Assam. Thacker, Spink and Co., Calcutta.

Hooker, J.D. 1872-1897. The flora of British India, 7 Vols. Secretary of State India. London.

Jain, S.K. and R.R. Rao 1977. A handbook of field and herbarium methods. Today and tomorrow's printers and publishers

Kanjilal, U.N., P.C. Kanjilal and A. Das 1934-1940. Flora of Assam, 5 Vols. Govt. of Assam. Shillong.

Kumar, S., S. Goyal and F. Parveen 2003. Ethnomedico-botany of household remedies of Kolayat tehsil in Bikaner district, Rajasthan. Indian Journal of Traditional Knowledge 2(4): 357.

Mitra, S. and S. Mukherjee 2010. Ethnomedicinal uses of wild plants of North Bengal plain for gastro-intestinal problems. Indian Journal of Traditional Knowledge 9(4): 705-712.

Saikia, B., S.K. Borthakur and N. Saikia 2010 Medico-ethnobotany of Bodo tribals in Gohpur of Sonitpur District, Assam. Indian Journal of Traditional Knowledge 9(1): 52-54.

Sajem, A.L. and K. Gosai 2006. Traditional use of medicinal plants by the Jaintia tribes in North Cachar Hills district of Assam, northeast India Journal of Ethnobiology and Ethnomedicine 2(33), doi:10.1186/1746-4269-2-33.

Sajem, A.L., J. Rout and M. Nath 2008. Traditional Tribal knowledge and Status of some Rare and Endemic Medicinal, Plants of North Cachar Hills District of Assam, Northeast India. Ethnobotanical Leaflet 12: 261-275. 